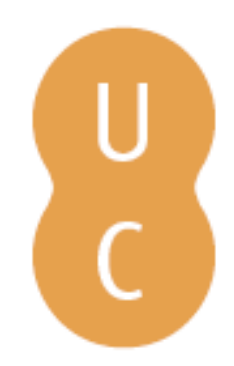

\title{
Rompalina
}

\section{Virgílio e a invenção da paisagem simbólica}

Autor(es): $\quad$ Cerqueira, Luís M. G.

Publicado por: Associação Portuguesa de Estudos Clássicos; Imprensa da

URL

persistente: URI:http://hdl.handle.net/10316.2/31768

DOI: $\quad$ DOI:http://dx.doi.org/10.14195/978-989-721-069-3_17

Accessed : $\quad$ 26-Apr-2023 13:48:52

A navegação consulta e descarregamento dos títulos inseridos nas Bibliotecas Digitais UC Digitalis, UC Pombalina e UC Impactum, pressupõem a aceitação plena e sem reservas dos Termos e Condições de Uso destas Bibliotecas Digitais, disponíveis em https://digitalis.uc.pt/pt-pt/termos.

Conforme exposto nos referidos Termos e Condições de Uso, o descarregamento de títulos de acesso restrito requer uma licença válida de autorização devendo o utilizador aceder ao(s) documento(s) a partir de um endereço de IP da instituição detentora da supramencionada licença.

Ao utilizador é apenas permitido o descarregamento para uso pessoal, pelo que o emprego do(s) título(s) descarregado(s) para outro fim, designadamente comercial, carece de autorização do respetivo autor ou editor da obra.

Na medida em que todas as obras da UC Digitalis se encontram protegidas pelo Código do Direito de Autor e Direitos Conexos e demais legislação aplicável, toda a cópia, parcial ou total, deste documento, nos casos em que é legalmente admitida, deverá conter ou fazer-se acompanhar por este aviso.

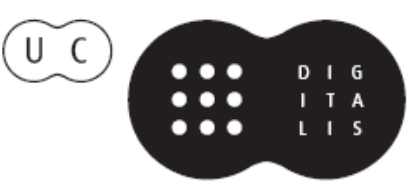




\section{Espaços e Paisagens}

\section{Antiguidade Clássica e Heranças Contemporâneas}

Vol. I Línguas e Literaturas. Grécia e Roma

Francisco de Oliveira, Cláudia Teixeira, Paula Barata Dias (coords.)

IMPRENSA DA UNIVERSIDADE DE COIMBRA 


\title{
VIRGÍLIO E A INVENÇÃO DA PAISAGEM SIMBÓLICA
}

\author{
Luís M. G. Cerqueira \\ Universidade de Lisboa
}

\begin{abstract}
Virgil's landscape is used, an innovative way in ancient literature, as a literary resource, an element rather active than passive, closely connected with the character's psychology and with the action, working together with other literay procedures towards an artistic creation of great unity and aesthetic effectivness.
\end{abstract}

Keywords: Aeneis, Virgil's landscape, Virgil's literary art.

Palavra-chave: Eneida, arte literária de Virgílio, paisagens de Virgílio.

A utilização da paisagem na obra de Virgílio é uma novidade na literatura antiga. Nos seus modelos mais óbvios, a paisagem era "o resto", discreto pano de fundo de que se destacavam os vultos grandiosos dos heróis homéricos, Arcádia utópica, refúgio literário de almas sensíveis, espaço idealizado adequado ao canto, mais uma entidade literária do que um espaço físico, mas ainda aí cenário, complemento circunstancial, o lugar onde qualquer coisa se passa.

Mas em Virgílio, especialmente na épica, a paisagem assume um papel de relevo, concertado com recursos artísticos variados, concorrendo para um resultado de conjunto que, ao ser analisado, se torna ainda mais claramente genial, muito para além da eficácia estética imediata que experimentamos num primeiro momento de leitura.

A paisagem vergiliana não é apenas o lugaronde decorrem os acontecimentos, mas assume uma relação sistemática não só com a psicologia das personagens, mas com a própria acção, remetendo para ela, substituindo-a, ecoando-a, compensando-a. Torna-se assim símbolo, objecto em relação com outro objecto, matriz de identificação.

Esta correspondência simbólica atinge em Virgílio uma dimensão, em extensão e qualidade, que não encontra paralelo na literatura antiga, e que constitui uma inovação importante, que designarei por invenção da paisagem simbólica: a paisagem torna-se um recurso estilístico. A análise e a tomada de consciência da multiplicidade de processos envolvidos no gesto poético e da sua coerência e eficácia suscita obviamente a admiração intelectual pelo génio do artista, mas sobretudo eleva a experiência estética inicial a um patamar de 
compreensão que torna o estudo da literatura um prazer não só renovado mas intensificado pelo aprofundamento.

Procuramos compreender esse funcionamento da paisagem através do estudo de alguns passos representativos.

\title{
1. A paisagem - aç̧ão
}

Expliquemos o aparente paradoxo. O exemplo é retirado dos versos finais da Bucólica I, em que dialogam dois pastores, Títiro e Melibeu, um numa situação precária de expulsão das suas terras na sequência da guerra civil e outro que toca flauta tranquilamente refastelado sub tegmine fagi. No diálogo esclarecem-se as razões da situação de um e outro. No final, o pastor Títiro faz um convite ao infortunado Melibeu, oferecendo-lhe a sua comida rústica e uma cama, rústica também ela, para descansar nessa noite. É uma proposta de solidariedade e reconciliação, que ultrapassa sem dúvida as suas pessoas particulares para se estender às facções da guerra civil numa Itália devastada.

Não temos a resposta de Melibeu. Importa o gesto benévolo, solidariedade que ecoa numa desejada reconciliação nacional. Temos isso sim, a descrição de uma paisagem no final da fala de Títiro.

\author{
Tityrus \\ Hic tamen hanc mecum poteras requiescere noctem \\ fronde super viridi. sunt nobis mitia poma, \\ castaneae molles et pressi copia lactis, \\ et iam summa procul villarum culmina fumant \\ maioresque cadunt altis de montibus umbrae.
}

Os cimos dos telhados fumegam, com a preparação do jantar, e as sombras do anoitecer estendem-se por sobre as terras.

Não se trata apenas de um argumento bem intencionado para convencer Melibeu a ficar e aceitar o convite, nem sequer da invenção do crepúsculo como tópico literário: em conjunto com as nasais do verso, com o ritmo sereno dos espondeus, as conotações de aconchego e acolhimento da paisagem, com a fusão dos elementos da paisagem no lusco fusco do entardecer, estes versos são, precisamente através da dimensão literária, a pedra de fecho da abóboda que se foi construindo na primeira bucólica. A antítese das situações de Títiro e Melibeu, cuja oposição, alternada em versos amebeus, estrutura todo o poema, resolve-se finalmente.

A descrição da paisagem nos dois últimos versos da fala de Títiro é certamente reflexo das intenções benévolas da personagem, mas é muito mais do que isso: é já a resposta de Melibeu, e uma conciliação não só dos pastores que se entreajudam mas simbolicamente um modelo de reconciliação nacional, 
pacificação almejada de oposições que se esfumam tal com os contornos das coisas neste entardecer.

A paisagem torna-se assim acção, num patamar simbólico. Esta função da paisagem é absoluta novidade.

\title{
2. Reflexo da psicologia das personagens
}

Para os Românticos a paisagem vai ser um estado de alma, mas a invenção do conceito é um pouco mais antiga. Encontramo-la já em alguns autores anteriores a Virgílio ${ }^{1}$. Vejamos a descrição do porto de Cartago, A. 1. 159-169 imitatio da descrição homérica do porto de Ítaca, Od., 13, 96-106:

\author{
Est in secessu longo locus: insula portum \\ efficit obiectu laterum, quibus omnis ab alto \\ frangitur inque sinus scindit sese unda reductos. \\ Hinc atque hinc vastae rupes geminique minantur \\ in caelum scopuli, quorum sub vertice late \\ aequora tuta silent; tum silvis scaena coruscis \\ desuper horrentique atrum nemus imminet umbra. \\ Fronte sub adversa scopulis pendentibus antrum, \\ intus aquae dulces vivoque sedilia saxo, \\ nympharum domus: hic fessas non vincula navis \\ ulla tenent, unco non alligat ancora morsu.
}

Debaixo do elemento vegetal de Homero, uma oliveira, não há risco nem perigo, mas Virgílio substituiu esta simplicidade solar por um bosque que está sobranceiro ao porto com o seu horrendo negrume. Imitando Homero, transfigura-o, e esta transfiguração passa fundamentalmente pelo aprofundamento da dimensão simbólica da paisagem. Imita a aprazível descrição homérica do porto de Ítaca, espaço de regresso, do amor fiel, com cores sombrias e ameaçadoras, pois estamos no espaço da paixão trágica DidoEneias, do amor traído ${ }^{2}$.

Por um lado exprime uma sensibilidade peculiar a Virgílio, mais complexo e subterrâneo, mais angustiado, se quisermos fazer a leitura de Joël Thomas, em que é concedida vida aos elementos da paisagem personificados: os rochedos erguem-se ao céus em ameaça, as águas fazem silêncio, os navios estão cansados, a âncora já não morde com o seu dente adunco. A paisagem toma

${ }^{1}$ Nomeadamente nos trágicos gregos. Cf. cena de abertura de Ésquilo, P.V.; Sófocles. Phil. 1453-68; e no O. C., 668-92, em que o coro de Sófocles exalta a serena beleza de Colono, onde o deambular angustiado de Édipo encontrará finalmente paz. Catulo, carmen 64, faz da paisagem de Naxos um eco dos sentimentos de Ariadne, utilizando a chamada figura de simpatia, que podemos definir como uma hipálage alargada.

${ }^{2}$ Análise comparativa do modelo homérico e do texto de Virgílio em L. Cerqueira (1995), "A imitatio vergiliana nos Saturnaliorum libri de Macróbio", Humanitas 47 651655. 
vida, apresenta-se cheia de tensões, mistérios e ameaças. Torna-se protagonista. $\mathrm{E}$ isto é caracteristicamente vergiliano.

Por outro lado, a descrição do porto de Cartago surge como um reflexo da psicologia das personagens e da acção, dando forma concreta e visível, através do simbolismo da paisagem, aos perigos que os exilados receiam em terra estranha e que de facto o episódio de Dido irá representar para um herói ainda não está na posse do discernimento e autonomia de vontade que só assumirá a partir da catábase do canto sexto. Reflexo indirecto, porque aparentemente visto pelos olhos do narrador, da psicologia das personagens, e simultaneamente prolepse e omen do que vai suceder em Cartago.

\title{
3. Prolepse da acção
}

O aspecto proléptico da paisagem vergiliana foi já sentido no tempo do poeta. A descrição de cada amanhecer tem em Virgílio uma formulação adequada às circunstâncias do que vai suceder nesse dia, conforme diz Sérvio a propósito de $A$. 11.183, citando Asínio Polião ${ }^{3}$.

A chegada a Itália e a entrada na foz do Tibre são o contraponto da chegada a Cartago, e isso é-nos também comunicado através do símbolo da tranquila paisagem marítima na viagem de Caieta à foz do Tibre ( $A$. 7-9):

Aspirant aurae in noctem, nec candida cursus

Luna negat, splendet tremulo sub lumine pontus,

Mas sobretudo a chegada à foz do Tibre, $A .7 .25$ ss:

\author{
Iamque rubescebat radiis mare et aethere ab alto \\ Aurora in roseis fulgebat lutea bigis, \\ cum uenti posuere omnisque repente resedit \\ flatus, et in lento luctantur marmore tonsae. \\ atque hic Aeneas ingentem ex aequore lucum \\ prospicit. bunc inter fuuio Tiberinus amoeno \\ uerticibus rapidis et multa flauu harena \\ in mare prorumpit. uariae circumque supraque \\ adsuetae ripis uolucres et fuminis alueo \\ aethera mulcebant cantu lucoque uolabant.
}

\footnotetext{
${ }^{3}$ Asinius Pollio dicit, ubique Vergilium in diei descriptione sermonem aliquem ponere aptum praesentibus rebus. Sérvio cita vários passos em que tal se verifica e R. Heinze, (1915), Vergil's epische Technik, Leipzig, alargou e aprofundou a verdade desta afirmação, e depois dele Gislason (1937), Die Naturschielderungen und Naturgleischnisse in Vergils Aeneis, diss. Münster, que alargou a análise desta correspondência às descrições em geral e aos símiles, ideias que foram retomadas e desenvolvidas por Viktor Pöschl (1950), Vergils Dichtkunst. Innsbruck-Wien, cap. III. Utilizámos a tradução inglesa, The art of Vergil. Images and symbol in the Aeneid. The University of Michigan, 1970.
} 
flectere iter sociis terraeque aduertere proras

imperat et laetus fuuio succedit opaco.

O ambiente ameno, o cantar das aves, a claridade desta manhã luminosa, tudo se conjuga para antecipar a conquista do Lácio, um lugar no mundo para este povo em demanda. Só a última palavra acena com os perigos da conquista, permitindo, por outro lado, a transição para o anúncio das guerras que encontramos nos versos seguintes.

A paisagem funciona, pois como criadora de tensões e momentos de serenidade que convergem com o rumo da acção e a intensificam, numa produção artística que resulta da reunião de múltiplos processos orientados num mesmo sentido, criando um gesto estético unificado e extraordinariamente eficaz.

\section{Recurso literário de contraste}

Se a paisagem era o lugar onde decorria a acção em Homero, em Virgílio vamos agora analisar uma paisagem em que a acção de facto não se passa, $A$. 4. 522-536:

\footnotetext{
Nox erat et placidum carpebant fessa soporem corpora per terras, siluaeque et saeua quierant aequora, cum medio uoluuntur sidera lapsu, cum tacet omnis ager, pecudes pictaeque uolucres, quaeque lacus late liquidos quaeque aspera dumis rura tenent, somno positae sub nocte silenti. at non infelix animi Phoenissa, neque umquam soluitur in somnos oculisue aut pectore noctem accipit: ingeminant curae rursusque resurgens saeuit amor magnoque irarum fluctuat aestu. sic adeo insistit secumque ita corde uolutat: 'en, quid ago? rursusne procos inrisa priores experiar, Nomadumque petam conubia supplex, quos ego sim totiens iam dedignata maritos?
}

O famoso monólogo nocturno de Dido, no canto quarto, é precedido por uma descrição da paisagem em que o sossego da noite serve para contrastar a angústia da rainha. Mas de facto esta paisagem não é o cenário em que desenrola a insónia da Fenícia, que está obviamente no conforto dos seus aposentos régios. A extensão das terras, a vastidão dos lagos, a amplidão das florestas, espaços extra-urbanos, até os longínquos astros são invocados das distâncias em que se encontram com o único fim de criar uma distensão que acentue o sofrimento amoroso da rainha, proporcionando um efeito de contraste. Tratase de uma moldura literária, que valoriza o quadro central. É certo que tem o seu modelo em Apolónio de Rodes, mas o que está aqui em causa é de natureza 
diferente: não uma oposição magia / mundo dos comuns mortais, campo / espaço urbano, mas a intensificação da coita amorosa da Fenícia.

\section{Recurso literário de compensação}

Pöschl assinala a busca de equilíbrio de zonas sombrias e de zonas luminosas dentro de cada um dos cantos. Há assim uma variação harmoniosa de ambientes, um ritmo das cores. Esta compensação foi assinalada sobretudo nos finais dos cantos, em que há um esforço por compensar o ambiente dominante do canto ${ }^{4}$.

No final do sombriamente violento e desesperado - e magnífico - canto segundo, surge a estrela Vésper, a acender uma luz de esperança; no final do canto quarto Íris vem aliviar o sofrimento de Dido, apressando-lhe a morte.

Esta harmonia musical dos opostos manifesta também uma mundividência estóica: o poeta assume uma continuidade cósmica e histórica em que nenhum princípio é dominante e em que os contrastes se unificam numa entidade superior.

A paisagem assume também ela esta função de equilíbrio composicional, contribuindo para uma harmonia de carácter musical. Assim, aparece-nos normalmente uma descrição da paisagem de carácter mais luminoso, após um episódio especialmente violento e vice-versa : o canto sétimo, que, como vimos, começa com o locus amoenus da optimista chegada à foz do Tibre, termina com o adensar das nuvens da guerra a travar; no final do canto nono, Turno, encurralado dentro do acampamento troiano e acossado por todos os lados com golpes que caem sobre ele como granizo, deixando-o a suar e sem fôlego, salta para o rio, que o "recebe no seu abismo louro, leva-o nas suas águas macias e devolve-o aos companheiros, alegre, lavado do sangue dos combates"

A paisagem aqui, novamente personificada, interage com a acção humana, criando um equilíbrio para a violência do episódio. A paisagem não é um estado de alma: é alma, tem alma, dinâmica autónoma e com consequências, não é mero cenário ou espelho. Da sua tradicional função passiva, foi elevada por Virgílio a um elemento activo da diegese.

\section{Criação de distensão rítmica para enquadrar momento importante da aç̧ão}

O canto décimo reveste-se de extrema importância para a ideologia da Eneida: no tropel dos combates, temos personagens cujo comportamento define uma mundividência e será a razão dos seus destinos, pois é essa a decisão de Júpiter no concílio inicial do canto décimo: fata sua uiam inuenient, e são os homens que os definem neste canto. Mezêncio é o vilão da Eneida, muito mais

\footnotetext{
${ }^{4}$ Esta ideia de um equilíbrio de chiaroscuro é desenvolvida por Pöschl em Vergils Dichtkunst, cap. III, com exemplificação. O nosso contributo consiste apenas em assinalar o papel da paisagem neste procedimento.

${ }^{5}$ Ille suo cum gurgite flaud accepit uenientem ac mollibus extulit undis/ et laetum sociis abluta caede remisit. A. 9. 816-8.
} 
que Turno, que defende os seus direitos, embora sem respeito pelo adversário, o que, mesmo funcionalmente, ditará o seu destino. Mas Mezêncio é a tirania personificada, a crueldade desnecessária, o homem desligado do seu povo e que não respeita os deuses, contemptor diuum, confiado apenas na força do seu braço $^{6}$. E assim Mezêncio é de facto o anti-Eneias, a encarnação do furor, símbolo de um estádio civilizacional primitivo e reprovável, tal como Eneias é símbolo da pietas. Daí a relevância da sua tomada de consciência e da sua destruição no contexto da ideologia da Eneida.

Afastado do combate por um ferimento e protegido na retirada pelo filho, que se expõe assim à morte, Mezêncio encontra-se numa margem, em que se sente uma pausa marcada, no meio do frenesim dos combates e da vertigem da morte, através de uma descrição em que as armas e homens se misturam com a Natureza (A.10.833-842):

\begin{abstract}
Interea genitor Tiberini ad fluminis undam uulnera siccabat lymphis corpusque leuabat arboris acclinis trunco. procul aerea ramis dependet galea et prato grauia arma quiescunt. stant lecti circum iunenes; ipse aeger anhelans colla fouet fusus propexam in pectore barbam; multa super Lauso rogitat, multumque remittit qui reuocent maestique ferant mandata parentis. at Lausum socii exanimem super arma ferebant flentes, ingentem atque ingenti uulnere uictum.
\end{abstract}

A acção violenta "agarra-se" literalmente à paisagem, que havíamos esquecido e desaparecera no clímax dos combates e das androctasias. Tal como as armas repousam no prado, nos ramos de uma árvore, tal como Mezêncio se recosta num tronco ou lava as ferida com a água do rio, assim também a acção vai repousar, agarrar-se a esta paisagem, que é margem e afastamento, propiciadora da reflexão e da compreensão, impossíveis na confusão da guerra. Mais do que uma pausa, a paisagem é aqui uma "travagem", assumindo uma função relevante, possibilitando e salientado a "conversão" de Mezêncio.

A evolução no sentido da criação do espaço reflexivo é também proporcionada pelo contraste entre a vivacidade do movimento da instante ansiedade paterna, em sobressalto devido à inquietação pela sorte do filho (multa rogitat, multum remittit), e (at) o movimento lento, pesado, do cortejo de companheiros que trazem o corpo exanimem, privado de movimento.

Esta pausa tem uma função rítmica importante: proporciona o espaço e o distanciamento que permitem a " conversão" de Mezêncio, que, perante o cadáver do filho, num misto de culpa e de vergonha, reconhece o erro que foi a sua vida e parte para a batalha para matar ou morrer, o que é menos relevante

\footnotetext{
${ }^{6}$ A. 7.648; 8.7; e 482 .
} 
do que a tomada de consciência do seu erro, que é assumido de forma extensa e dramática $(A .10 .834-845)$ :

\author{
agnouit longe gemitum praesaga mali mens. \\ canitiem multo deformat puluere et ambas \\ ad caelum tendit palmas et corpore inhaeret. \\ 'tantane me tenuit uiuendi, nate, uoluptas, \\ ut pro me hostili paterer succedere dextrae, \\ quem genui? tuane baec genitor per uulnera seruor \\ morte tua uiuens? heu, nunc misero mibi demum \\ exitium infelix, nunc alte uulnus adactum! \\ idem ego, nate, tuum maculaui crimine nomen, \\ pulsus ob inuidiam solio sceptrisque paternis \\ debueram patriae poenas odiisque meorum: \\ omnis per mortis animam sontem ipse dedissem!
}

A morte generosa de Lauso é a causa para a mudança no pai, mas foi necessário criar artisticamente um espaço para que esta mudança tivesse lugar e o devido impacto, exigido pela sua importância estrutural, e isso é conseguido através da intromissão subreptícia da paisagem. O carácter imóvel desta paisagem natural contagia o elemento humano e o leitor apercebe-se de uma pausa assinalável no ritmo discursivo, e é em parte por isso que esta cena se nos fixa na memória. 